\title{
ESTUDO COMPARATIVO ENTRE ATIVIDADES URBANAS E AGRÍCOLAS SOBRE A QUALIDADE DA ÁGUA DO RIO LAJEADO BONITO EM PINHALZINHO-SC
}

\author{
Diego Alex Mayer ${ }^{1}$
}

\author{
Gilmar de Almeida Gomes²
}

\author{
Weber da Silva Robazza ${ }^{3}$
}

RESUMO: O objetivo deste trabalho é caracterizar e compreender de que forma o sistema aquático comporta-se com as alterações provocadas pelo homem. A área de estudo localiza-se no município de Pinhalzinho, sendo que o córrego estudado é conhecido como Rio Lajeado Bonito. A caracterização foi realizada através de análises físicas e químicas como: condutividade elétrica $(\mathrm{CE}), \mathrm{pH}$, temperatura, cloreto, fósforo, demanda química de oxigênio (DQO) e dureza no período de março a julho de 2010. Com os resultados obtidos verificamos que o Ponto 2 localizado na área urbana apresentam maior antropogenia do que os pontos localizados na área rural, pois nestes pontos foram encontradas as maiores concentrações de cloreto, dureza, fósforo, CE e DQO. Isto indica que na área urbana o córrego está sofrendo consideravelmente com a ação humana e uma das explicações para este fato é negligência da população com o meio ambiente. Essa ação antrópica também é verificada quando avaliamos o comportamento conservativo do íon cloreto em função da CE e da DQO. A partir deste trabalho podemos verificar que a área urbana contribui mais para o impacto ambiental do que a área rural, devido a maior mistura de íons com as águas do córrego.

Palavras-chave: Impacto Ambiental. Córregos. Íons Inorgânicos.

\footnotetext{
${ }_{1}^{1}$ Acadêmico de Engenharia de Alimentos, Universidade do Estado de Santa Catarina. diegoalexmayer@yahoo.com.br

${ }^{2}$ Dr. em Química, Professor da Universidade do Estado de Santa Catarina. gilmargomess@yhaoo.com.br

${ }^{3}$ Dr. Em Física, Professor da Universidade do Estado de Santa Catarina. wrobazzi@yahoo.com.br
} 


\section{INTRODUÇÃO}

A água doce até as últimas décadas era considerada um bem infinito, mas com o rápido desenvolvimento industrial, aumento populacional e consequentemente expansão agrícola a sua qualidade e disponibilidade diminui drasticamente (MARQUEZ, et al., 2007).

A qualidade da água esta diretamente relacionada com a sua capacidade em ser um solvente universal. Devido a esta capacidade ela solubiliza muita das substâncias que são necessárias para a existência de vida tanto no meio aquático quanto no meio terrestre, porém, esta propriedade também faz com que ela torna-se o destino de outros componentes que se comportam como poluentes.

Em áreas onde são desenvolvidas práticas agrícolas, o uso do solo contribui consideravelmente sobre as características físicas, químicas e biológicas da água, pois as concentrações naturais de nitrato, fósforo e sulfato são alterados por esta prática (PISSARRA, et al., 2008).

Os processos de industrialização e urbanização também causam impacto ambiental, pois aumentam a concentração de poluentes como nitrogênio, fósforo, cloretos, sulfatos, metais pesados e solventes orgânicos nas águas de nascentes e córregos (JIANG, Y. et al., 2009).

A presença de poluentes em nascentes e córregos pode gerar problemas aos organismos que habitam estes ambientes e alterar suas estruturas populacionais. Esses contaminantes podem provocar a morte de peixes e algas, devido à ineficiência desses ecossistemas em manter seus processos autodepurativos, acarretando a perda de qualidade da água e ocasionando sérios problemas de saúde para a população humana que consome essa água (ROCHA e MARTIN, 2005).

Atualmente a degradação dos corpos d'água, esta deixando de ser uma característica comum em grandes cidades e esta acontecendo em maior grau em cidades menores e pouco industrializadas. Por esse motivo é muito importante estudar e identificar as fontes de poluição em córregos localizados em cidades menores, pois eles 
são os principais fornecedores de água para a população, indústria e agricultura destes municípios.

O objetivo deste trabalho é estudar e compreender o fluxo químico hidrológico no Rio Lajeado Bonito do município de Pinhalzinho, Santa Catarina, em diferentes épocas do ano através de análises físicas e químicas desse córrego.

\section{MATERIAIS E MÉTODOS}

\section{1. Área de estudo e amostragem}

A área de estudo localiza-se no município de Pinhalzinho em Santa Catarina com uma latitude $26^{\circ} 50^{\prime} 53.95^{\prime \prime}$ sul e a uma longitude $52^{\circ} 59^{\prime} 21.37^{\prime \prime}$ oeste, estando a uma altitude 515 metros acima do nível do mar. Este possui uma área de 128,298 $\mathrm{Km}^{2}$ tendo uma população de aproximadamente 16332 habitantes (IBGE, 2010) e sua economia distribui-se entre os setores da indústria, agricultura e comércio, predominando o setor industrial.

Os estudos foram realizados no Rio Lajeado Bonito, Figura 1, que é um rio que tem como característica principal sua nascente localizada na área urbana e o restante de seu percurso localizado na área rural.

Neste rio foram determinados seis pontos de coleta, três localizados na área urbana, pontos 1, 2 e 3, e três na área rural, pontos 4, 5 e 6, em uma distância aproximada de $10 \mathrm{Km}$. O período de estudo foi de março a julho de 2010. Foi realizada uma coleta mensal dependendo das principalmente das precipitações. 


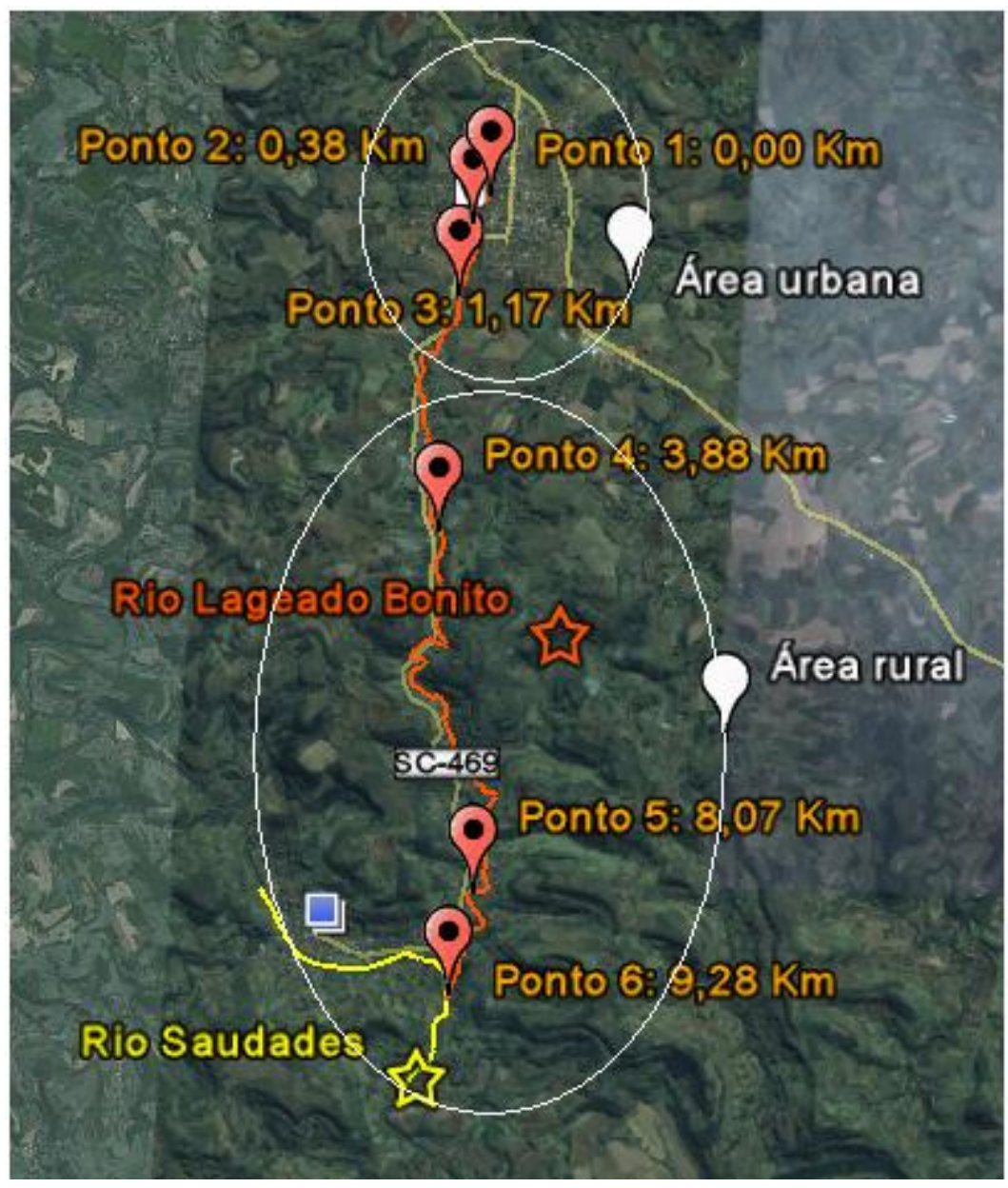

Figura 1 - Área de estudo - Rio Lajeado Bonito - Pinhalzinho - SC

\subsection{Metodologia}

Todas as amostras foram coletadas após as precipitações, pois se acreditava que as precipitações contribuíam de forma positiva para o aumento da concentração de íons no meio aquático, devido a lixiviação causada pelo meio urbano e pelas culturas agrícolas.

As amostras foram coletadas e armazenadas em garrafas de polietileno tereftalato (PET) de $500 \mathrm{~mL}$ previamente higienizadas e armazenadas em caixa isopor com gelo com temperatura de aproximadamente $4^{\circ} \mathrm{C}$, para posterior análise no laboratório.

No local da coleta foram determinados os seguintes parâmetros físicos, temperatura ambiente e temperatura da amostra através de um termômetro de mercúrio. 


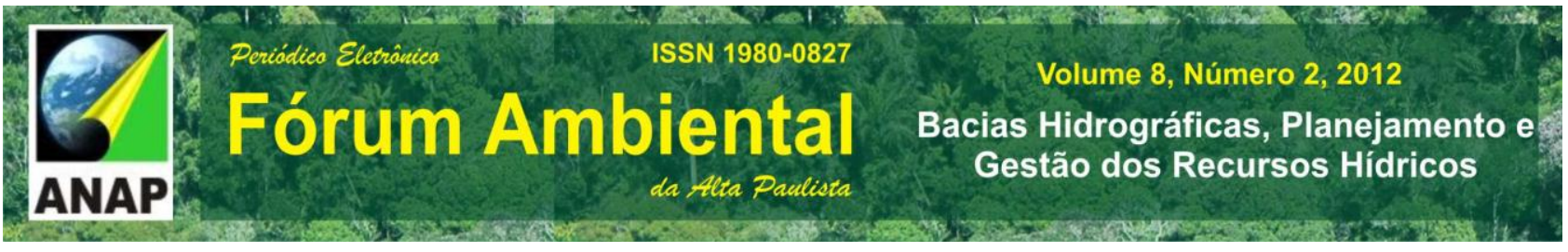

No laboratório foram determinados os demais parâmetros físico-químicos, como: condutividade elétrica (CE), por um condutivímetro, marca Quimis (Q-795 A2); pH, através de um pHmetro, marca Quimis (Q-400 MT); cloreto, dureza e sólidos totais, através de métodos descritos por ZENEBON, et al. (1976), fósforo pelo método descrito por AFKHAMI, et al., (2009) e a demanda química de oxigênio (DQO) pelo método descrito por APPLETON e TYSON, (1986). Todos os parâmetros foram determinados em duplicata. Também foi observada a precipitação através de um pluviômetro instalado perto da Universidade.

\section{RESULTADOS E DISCUSSÃO}

$\mathrm{Na}$ Tabela 1, são mostrados a média dos resultados de $\mathrm{pH}, \mathrm{CE}$, temperatura, dureza, cloreto, fósforo e DQO em vários pontos do Rio Limeira.

Podemos perceber de forma bem clara que os pontos localizados na área urbana, principalmente o Ponto 2, apresentam os maiores teores de dureza, cloreto, CE, fósforo e DQO. Isto indica que a área urbana produz efeitos antrópicos maiores sobre o córrego do que a área rural. Essa antropogenia pode estar relacionada com a mistura de esgotos domésticos e hidrossanitários com as águas do Rio Lajeado Bonito, que pode estar relacionado com a alta densidade demográfica e industrialização.

Também é observado na Tabela 1, que na área urbana os valores de pH são menores, indicando mistura de efluentes de caráter mais ácidos com as águas do córrego do que na área rural.

Tabela 1 - Resultados da dureza, cloreto, condutividade elétrica, pH, fósforo e DQO encontrados no Rio Lajeado bonito em diferentes épocas do ano.

\begin{tabular}{|c|c|c|c|c|c|c|c|}
\hline & $\begin{array}{c}\text { Pontos } \\
\text { (Km) }\end{array}$ & $\begin{array}{l}\text { Dureza } \\
\left(\mathrm{mg}^{-1} \mathrm{~L}^{-1}\right)\end{array}$ & $\begin{array}{c}\mathrm{Cl}^{-} \\
\left(\mathrm{mg} \cdot \mathrm{L}^{-1}\right)\end{array}$ & $\begin{array}{c}C E \\
\left(m g \cdot L^{-1}\right)\end{array}$ & $\mathrm{pH}$ & $\begin{array}{l}\text { Fósforo } \\
\left(\mathrm{mg}^{-1} \mathrm{~L}^{-1}\right)\end{array}$ & $\begin{array}{c}\mathrm{DQO} \\
\left(\mathrm{mgO}_{2} \cdot \mathrm{L}^{-1}\right)\end{array}$ \\
\hline \multirow{2}{*}{$\begin{array}{l}\text { Área } \\
\text { Urbana }\end{array}$} & $\begin{array}{c}1 \\
(0,00)\end{array}$ & $\begin{array}{l}10,40 \\
( \pm 0,68)\end{array}$ & $\begin{array}{l}12,00 \\
( \pm 0,00)\end{array}$ & $\begin{array}{c}102.00 \\
( \pm 5,72)\end{array}$ & $\begin{array}{c}7,15 \\
( \pm 0,40)\end{array}$ & $\begin{array}{c}0,96 \\
( \pm 0,36)\end{array}$ & $\begin{array}{l}34,28 \\
( \pm 3,10)\end{array}$ \\
\hline & $\begin{array}{c}2 \\
(0,38)\end{array}$ & $\begin{array}{l}13,38 \\
( \pm 2,54)\end{array}$ & $\begin{array}{l}17,25 \\
( \pm 2,22)\end{array}$ & $\begin{array}{c}173,00 \\
( \pm 5,72)\end{array}$ & $\begin{array}{c}6,99 \\
( \pm 0,12)\end{array}$ & $\begin{array}{c}3,46 \\
( \pm 1,99)\end{array}$ & $\begin{array}{l}77,23 \\
( \pm 8,96)\end{array}$ \\
\hline
\end{tabular}

VIII Fórum Ambiental da Alta Paulista, v. 8, n.2, 2012, p. 130-138. 


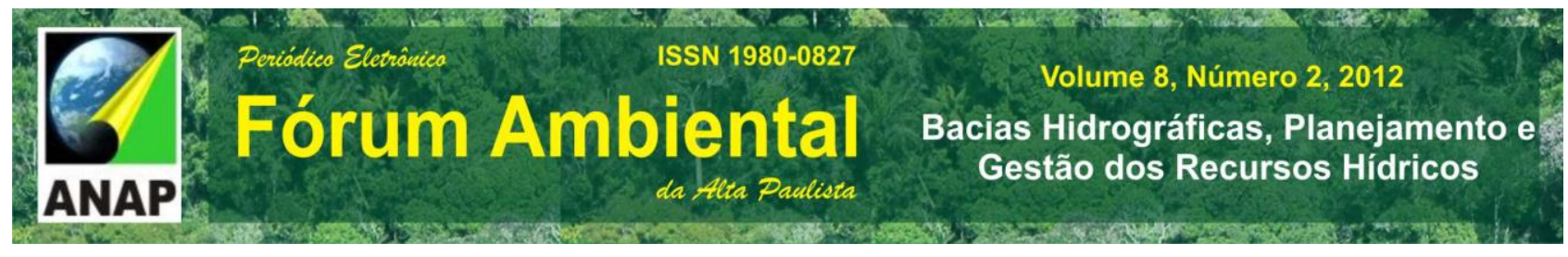

\begin{tabular}{c|ccccccc} 
& $\mathbf{3}$ & 10,32 & $\begin{array}{c}13,75 \\
( \pm 0,45)\end{array}$ & $\begin{array}{c}133,25 \\
( \pm 0,96)\end{array}$ & $\begin{array}{c}7,56 \\
( \pm 0,07)\end{array}$ & $\begin{array}{c}0,66 \\
( \pm 0,10)\end{array}$ & $\begin{array}{c}28,07 \\
( \pm 3,62)\end{array}$ \\
\hline & $\begin{array}{c}\mathbf{4} \\
(3,88)\end{array}$ & $\begin{array}{c}8,19 \\
( \pm 0,74)\end{array}$ & $\begin{array}{c}9,75 \\
( \pm 0,50)\end{array}$ & $\begin{array}{c}88,75 \\
( \pm 9,60)\end{array}$ & $\begin{array}{c}7,62 \\
( \pm 0,05)\end{array}$ & $\begin{array}{c}0,70 \\
( \pm 0,34)\end{array}$ & $\begin{array}{c}19,32 \\
( \pm 9,37)\end{array}$ \\
$\begin{array}{c}\text { Área } \\
\text { Rural }\end{array}$ & $\mathbf{5}$ & $\begin{array}{c}7,96 \\
(8,07)\end{array}$ & $\begin{array}{c}( \pm 1,13) \\
( \pm 0,96)\end{array}$ & $\begin{array}{c}74,00 \\
( \pm 7,07)\end{array}$ & $\begin{array}{c}7,70 \\
( \pm 0,11)\end{array}$ & $0,81( \pm 0,49)$ & $\begin{array}{c}18,18 \\
( \pm 7,43)\end{array}$ \\
& $\mathbf{6}$ & 7,72 & $\begin{array}{c}8,5 \\
( \pm 0,56)\end{array}$ & $\begin{array}{c}74 \\
( \pm 6,73)\end{array}$ & $\begin{array}{c}7,68 \\
( \pm 0,07)\end{array}$ & $\begin{array}{c}0,78 \\
( \pm 0,38)\end{array}$ & $\begin{array}{c}21,58 \\
( \pm 10,08)\end{array}$ \\
\hline
\end{tabular}

O que mais chama atenção são os parâmetros CE e DQO do Ponto 2, que possuem as maiores variação em relação a área rural. A alta condutividade observada tem relação direta com os outros íons estudados, pois quanto maior a concentração de íons em uma solução maior será a CE. A alta DQO indica a mistura de matéria orgânica com as águas do córrego nesse local.

Em estudo similar realizado em uma subárea da cidade de Kampala, Uganda, por Haruna et al., (2005), os autores observaram altas concentrações de cloreto na área urbana e apontaram também que esse íon e proveniente da mistura de esgotos domésticos com as águas naturais.

Outra forma de observar se um sistema esta sofrendo efeitos antrópicos é analisar a combinação de vários parâmetro em conjunto como no trabalho de Kim et al. (2002), onde esses autores estudaram a concentração do íon cloreto em função de outros parâmetros como CE e sulfato. Isso pode ser feito, pois o cloreto é um íon conservativo, significando que se os outros parâmetros tiverem o mesmo comportamento do que o cloreto, ou seja, seguir a mesma função, podemos afirmar que não existe impacto ambiental, por outro lado se tiverem comportamento diferente é um indicar de impacto ambiental.

Na Figura 2 é apresentado o íon cloreto em função da CE, pode-se observar que os pontos localizados na área urbana apresentam as maiores concentrações tanto de íon cloreto quanto de CE. As altas concentrações de íons neste ponto indicam alta ação antropogenica, pois a concentração de cloreto e a CE teve um aumento em relação ao 
Ponto 1, sendo que do Ponto 1 ao Ponto 2 ocorreu alguma mistura entre as águas do córrego e de esgotos domésticos ou hidrossanitários.

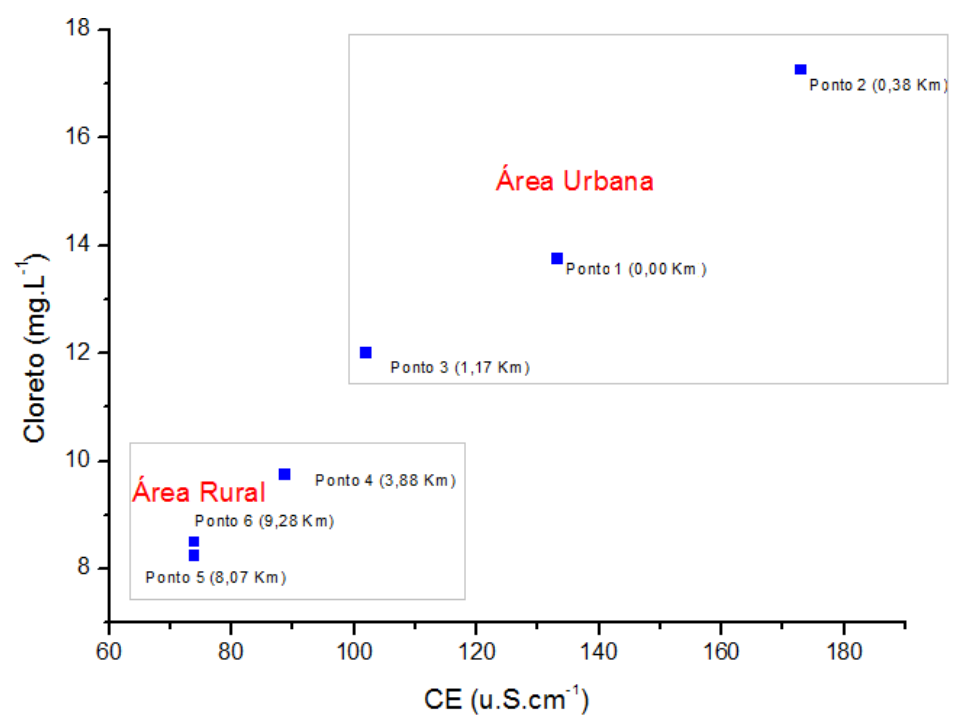

Figura 2 - Concentração do íon cloreto em função da CE entre a área urbana e a rural.

Na Figura 3 é mostrada a concentração do íon cloreto em função da DQO, e também é observado que as águas da área urbana apresentam maiores teores de cloreto e DQO, esta relação também comprova alta ação antropogenica produzida pela área urbana. Comparando com a Figura 2 podemos observar que novamente o Ponto 2 apresenta maior impacto ambiental, pois a relação entre o íon cloreto e a DQO é a mais alta. Afirmando que entre o Ponto 1 para o Ponto 2 ocorreu mistura das águas do córrego com esgotos domésticos ou hidrossanitários. 


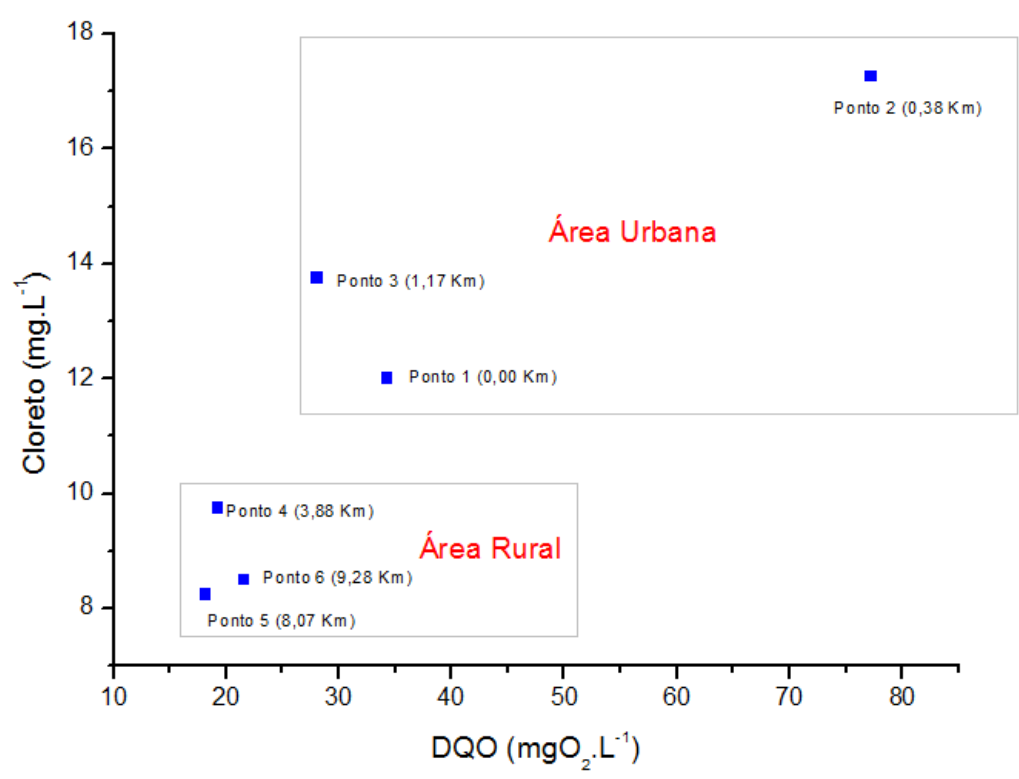

Figura 3 - Concentração do íon cloreto em função da DQO entre a área urbana e a rural.

Dessa forma podemos afirmar que a área urbana provoca maior impacto ambiental do que a área rural, porém devemos ter cuidado nesta afirmação, pois neste trabalho foi somente estudado alguns parâmetros, para se ter maior certeza dessa afirmação é necessário fazer outras análises como de defensivos agrícolas.

\section{CONCLUSÃO}

No córrego estudado, pode-se verificar elevados teores de cloreto, dureza, fósforo, CE e DQO na área urbana, principalmente no Ponto 2 que apresentou as maiores concentrações de íons. Isso indica que este local está sofrendo ação antropogênica devido ao mau uso dos recursos naturais e do mau direcionamento dos resíduos domésticos. E na medida com que a ruralização aumenta as concentrações de íons diminuem devido a uma possível diminuição significativa da mistura de íons com as águas do córrego. 


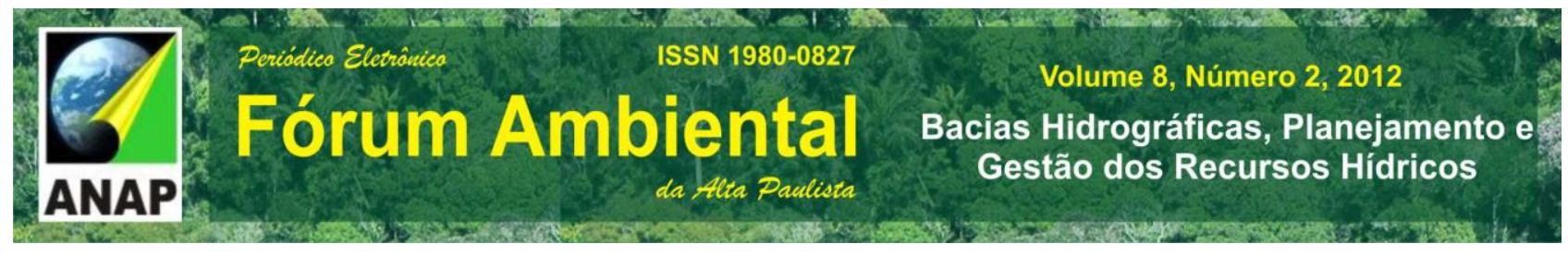

\section{REFERÊNCIAS}

AFKHAMI, A., NOROOZ-ASI, R. Cloud point extraction for the spectrophotometric determination of phosphorus (V) in water samples. Journal of Hazardous Materials, $v$. 167, p. 752-755, 2009.

HARUNA, R., EJOBI, F., KABAMBEZ, K. The quality of water from protected springs in Katwe and Kisenyi parishes, Kampala city, Uganda. African Health Sciences, v.5, n.1, p.14-20. 2005.

IBGE. Instituto Brasileiro de Geografia e Estatistica. Censo Demográfico. 2010. Disponível em: <http://www.ibge.gov.br/cidadesat/topwindow.htm?1>. Acesso em: 04 out. 2012.

JIANG, Y.; WU, Y.; GROVES, C.; YUAN, D. KAMBESIS, P. Natural and antfropogenic factors affecting the groundwater quality in the Nandong karst underground river system in Yunan, China. Journal of Contaminant Hydrology, v. 109, p.49-61, 2009.

KIM, K.; LEE, J. S.; OH, C.; HWANG, G.; KIM, J.; YEOo, S. KIM, Y.; PARK, S. Inorganic chemicals in an effluent-dominated stream as indicators for chemical reactions and streamflows. Journal of Hydrology, v.264, p.147-156. 2002.

MARQUEZ, M. N.; COTRIM, M. B.; PIRES, M. A. F.; FILH, O. B.; Avaliação do impacto da agricultura em áreas de proteção ambiental, pertencentes à bacia hidrográfica do Rio Ribeira de Iguape, São Paulo. Química Nova, v. 30, n. 5, p.1171-1178, 2007.

ROCHA, R. R. de A.; MARTIN, E. S. Análise preliminar do estado ambiental do córrego Água da Lavadeira, Rancharia-SP: Análise física e química da Água. Revista Eletrônica da Associação dos Geógrafos Brasileiros, v. 2, n. 2, p. 116-130, 2005.

ZENEBON, O.; PASCUET, N. S.; TIGLEA, P. Métodos Químicos e Físicos para Análise de Alimentos. Instituto Adolfo Lutz: São Paulo, 1976. 